\title{
The Influence of Thermomagnetic Treatment on the Magnetoelastic Characteristics of $\mathrm{Fe}_{61} \mathrm{Co}_{19} \mathrm{Si}_{5} \mathrm{~B}_{15}$ Amorphous Alloys
}

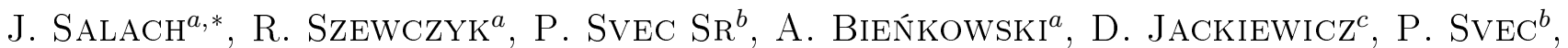
M. Nowicki ${ }^{a}$, W. Winiarski ${ }^{c}$, M. KaChNiARZ $^{a}$ And M. Gruszecka ${ }^{a}$

${ }^{a}$ Institute of Metrology and Biomedical Engineering, Warsaw University of Technology,

A. Boboli 8, 02-525 Warszawa, Poland

${ }^{b}$ Institute of Physics, Slovak Academy of Sciences, Dúbravská cesta 9, 84511 Bratislava 45, Slovak Republic

${ }^{c}$ Industrial Research Institute for Automation and Measurements, Al. Jerozolimskie 202, 02-486 Warszawa, Poland

\begin{abstract}
Information about magnetoelastic properties of newly developed amorphous magnetic alloys is very important from practical point of view, especially in the case of high permeability materials such as the $\mathrm{Fe}_{61} \mathrm{Co}_{19} \mathrm{Si}_{5} \mathrm{~B}_{15}$ amorphous alloy. In the case of such materials, effect connected with the influence of external stresses on the magnetic properties of the alloy should be tested. This paper presents experimental results of the magnetoelastic properties investigation of the $\mathrm{Fe}_{61} \mathrm{Co}_{19} \mathrm{Si}_{5} \mathrm{~B}_{15}$ amorphous alloy, annealed without magnetic field as well as in the magnetic field. Such thermo-magnetic treatment generated anisotropy has significant influence on the total free energy of magnetic material. In the magnetoelastic investigation, the compressive stress was applied to the ring shaped core, perpendicularly to the magnetizing field direction. Due to the fact, that cores with closed magnetic circuits were used, demagnetization did not change the balance of total free energy in the material.
\end{abstract}

DOI: $10.12693 /$ APhysPolA.127.617

PACS: $75.80 .+\mathrm{q}, 75.50 . \mathrm{Kj}$

\section{Introduction}

The magnetoelastic effect may be observed as the changes of flux density $B$ in the material (induced for the given value of magnetizing field $H_{\mathrm{m}}$ ) under the influence of mechanical stresses $\sigma$, caused by external force $F$. The $B(\sigma)_{H m}$ characteristics describe magnetoelastic properties of the material [1]. Sometimes the extreme on the $B(\sigma)_{H m}$ characteristic may be observed. This extreme is known as the Villari point [2]. It was confirmed that for compressive stress $\sigma$ corresponding to the Villari point, magnetostriction $\lambda_{\mathrm{s}}$ of the material changes its sign [3].

Iron-rich amorphous alloys [4], such as $\mathrm{Fe}_{61} \mathrm{Co}_{19} \mathrm{Si}_{5} \mathrm{~B}_{15}$ alloy, show high permeability and low value of coercive force. As a result, such alloys are used as the cores of inductive components of switching mode power supplies [5], as well as cores of the power and current transformers [6]. Moreover, the magnetic characteristics of iron-rich amorphous alloys change significantly under the influence of mechanical stresses [7]. These changes may be so high due to the fact that amorphous alloys do not have a crystalline structure. As a result, in the total balance of free energy of amorphous alloy sample, the energy of magnetocrystalline anisotropy is absent. This leads to a high stress sensitivity connected with the fact that significant changes of magnetic properties are caused by even relatively small stress induced magnetoelastic anisotropy energy.

${ }^{*}$ corresponding author; e-mail: j.salach@mchtr.pw.edu.pl
This paper presents the results of experimental investigation focused on the influence of compressive stresses on properties of the $\mathrm{Fe}_{61} \mathrm{Co}_{19} \mathrm{Si}_{5} \mathrm{~B}_{15}$ amorphous alloy in as-quenched and annealed state.

\section{Experimental method}

Investigation of influence of the thermomagnetic treatment on the magnetoelastic characteristics requires the methodology enabling obtainment of the uniform stresses $\sigma$ distribution in the ring shaped amorphous core. Moreover, the investigated core has to be wound by a magnetizing and sensing winding, to measure the magnetic hysteresis loop. Method enabling magnetoelastic tests of the ring-shaped amorphous alloy cores was developed previously [8]. Device for practical realization of magnetoelastic investigation is presented in Fig. 1.

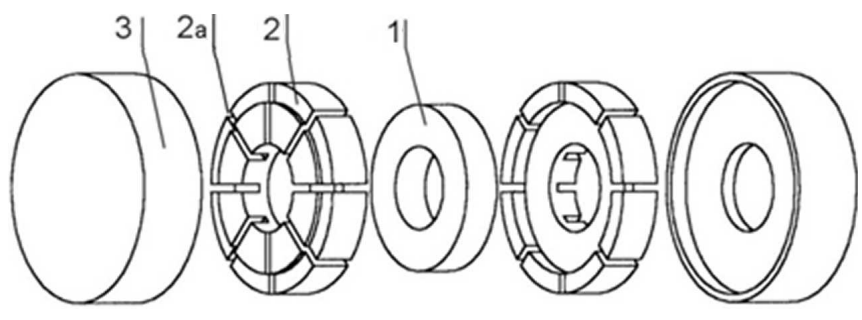

Fig. 1. Schematic diagram of the device for applying the uniform compressive stress to the ring core . 1 investigated ring core, 2 - nonmagnetic cylindrical fixture, $2 \mathrm{a}$ - grooves for windings, 3 - base backings.

The compressive force $F$ is applied to the investigated ring-shaped core (1) through base backings (3). 
Measuring and magnetizing windings are placed in grooves $(2 \mathrm{a})$ of the special, nonmagnetic cylindrical fixtures (2).

This method allows measurement of magnetoelastic characteristics of both bulk material rings and ribbon ring cores. It should be highlighted that device based on the idea presented in Fig. 1 enables application of uniform compressive stresses to the ring-shaped cores.

One possible example of furnace capable of transversal field annealing of ring-shaped magnetic circuits from rapidly quenched ribbons is a two-piece furnace with flat circular heaters made of the non-magnetic heating wires (Nicrothal). Ring-shaped core to be annealed is placed between the heaters containing a set of several thermocouples to control thermal gradient in the heated zone and the entire assembly is placed in a water-cooled gastight container in order to ensure a suitable annealing atmosphere (typically inert gas).

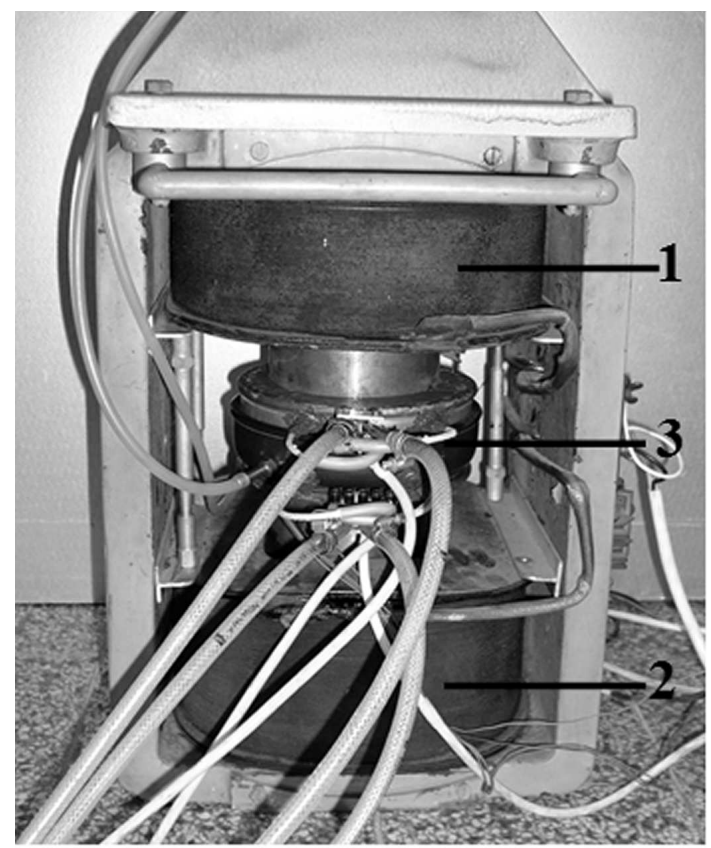

Fig. 2. Device for thermal annealing of ring-shaped cores in transversal magnetic field: 1,2 - electromagnet poles, 3 - furnace with ring-shaped core.

The height of such assembly can be as low as $80 \mathrm{~mm}$ and can be placed between the poles of a suitable electromagnet which can apply a field of up to $0.5 \mathrm{~T}$. Figure 2 shows the realization of such a device capable of annealing of ring-shaped cores with outer diameter of up to $130 \mathrm{~mm}$ and up to $25 \mathrm{~mm}$ height.

The experiment was performed on the two ring-shaped $\mathrm{Fe}_{61} \mathrm{Co}_{19} \mathrm{Si}_{5} \mathrm{~B}_{15}$ amorphous ribbon cores. Amorphous structure of material was confirmed by X-ray diffraction. The thickness of the ribbon was about $25 \mu \mathrm{m}$. One core was in as quenched state. Both cores were annealed in $410^{\circ} \mathrm{C}$ with and without perpendicular magnetic field, respectively. Value of applied magnetic flux density was $0.3 \mathrm{~T}$. The outside diameter of all samples was $32 \mathrm{~mm}$, inside diameter was $25 \mathrm{~mm}$ and height was $8 \mathrm{~mm}$. Measurements of the magnetoelastic characteristics were performed in temperatures $20^{\circ} \mathrm{C}$ for all samples.

\section{Results}

Figure 3 shows the influence of compressive stresses $\sigma$ on the shape of $B\left(H_{\sigma}\right.$ hysteresis loops of $\mathrm{Fe}_{61} \mathrm{Co}_{19} \mathrm{Si}_{5} \mathrm{~B}_{15}$ amorphous alloy. Under the compressive stresses $\sigma$ of up to $10 \mathrm{MPa}$, value of flux density $B$ increased, and the value of coercive field $H_{\mathrm{c}}$ does not change [9].

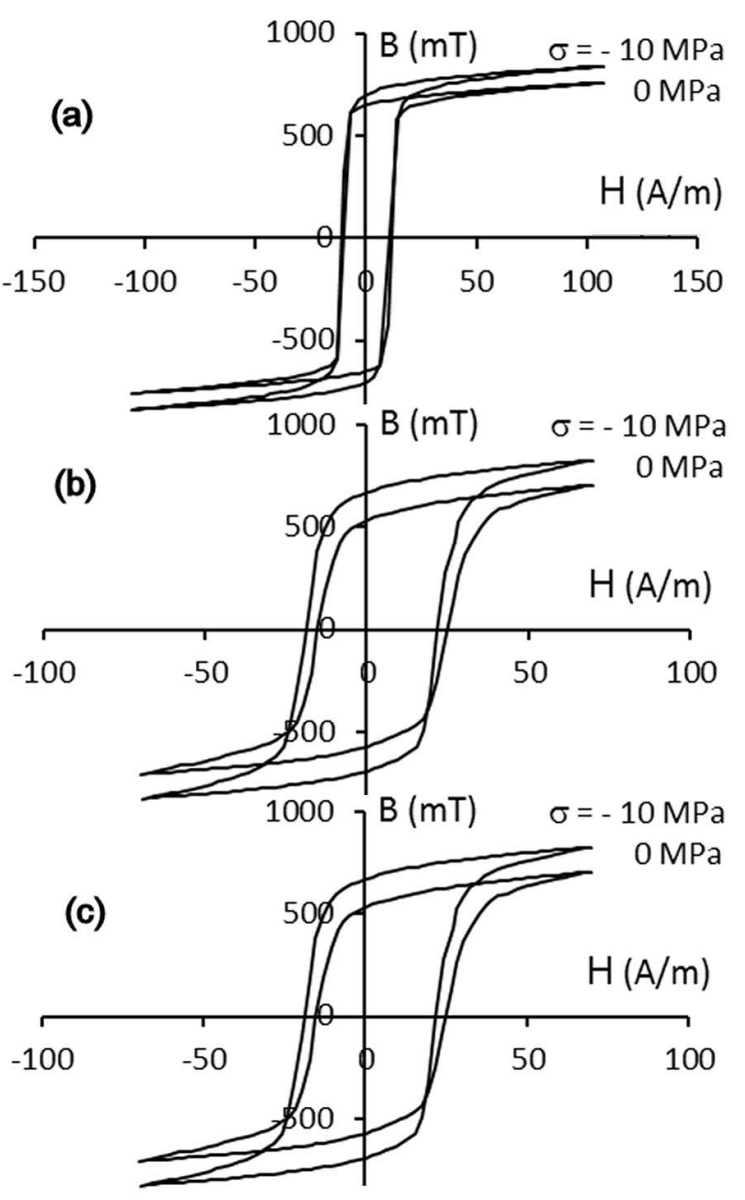

Fig. 3. The influence of the compressive stress $\sigma$ on the magnetic hysteresis loop $B(H) \sigma$ of $\mathrm{Fe}_{61} \mathrm{Co}_{19} \mathrm{Si}_{5} \mathrm{~B}_{15}$ amorphous alloy cores: (a) in as quenched state (b) annealed in $410{ }^{\circ} \mathrm{C}$ without magnetic flux density (c) annealed in $410{ }^{\circ} \mathrm{C}$ in $0.3 \mathrm{~T}$ magnetic field.

The magnetoelastic $B(\sigma)_{H m}$ characteristics of cores made of $\mathrm{Fe}_{61} \mathrm{Co}_{19} \mathrm{Si}_{5} \mathrm{~B}_{15}$ amorphous alloy are presented in Fig. 4. Under the influence of compressive stresses, the value of maximal flux density $B$ decreases. Based on these results the magnetoelastic sensitivity can be determined. Sensitivity was calculated as the relative change in the flux density of the sample for the full load range of 0 to $10 \mathrm{MPa}$. For core in as-quenched state, the magnetoelastic sensitivity is equal to $10 \%$. For core annealed 
in $410^{\circ} \mathrm{C}$ for one hour, the magnetoelastic sensitivity is equal to $15 \%$. For core annealed in $410^{\circ} \mathrm{C}$ for one hour in magnetic field, the magnetoelastic sensitivity is equal to $60.5 \%$.

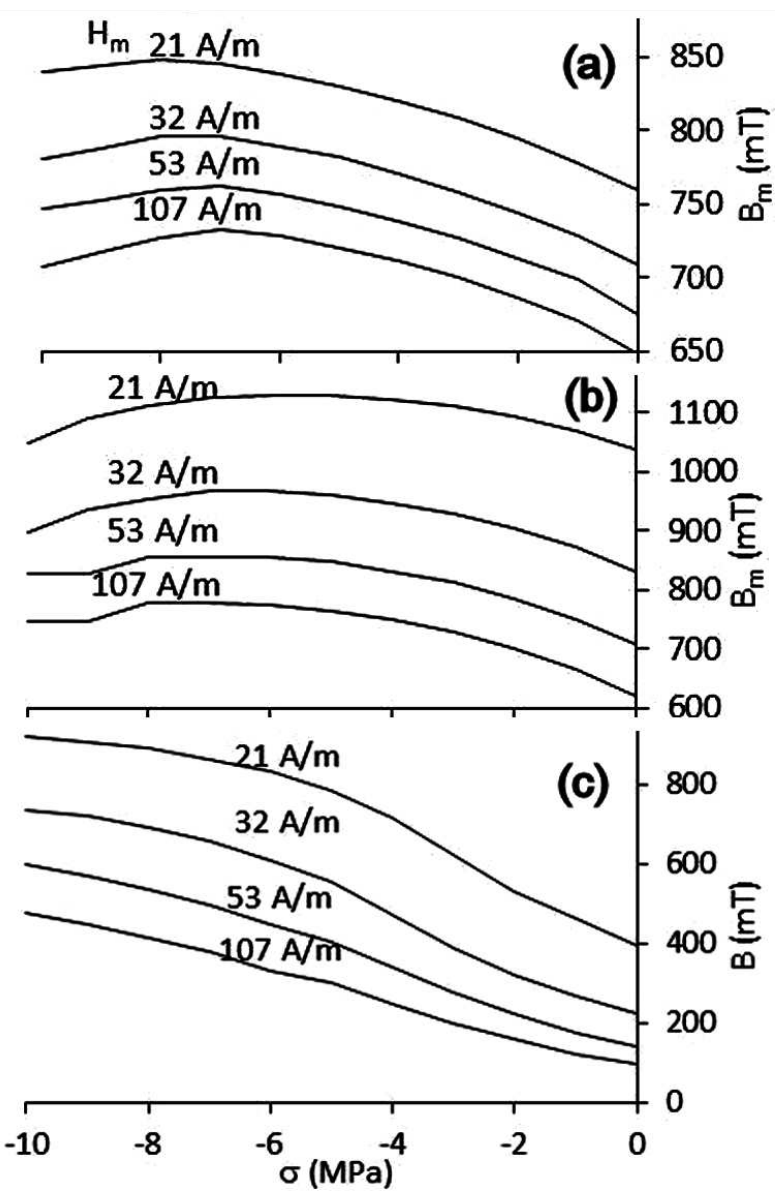

Fig. 4. The influence of the compressive stress $\sigma$ on the flux density $B$ achieved for the given value of magnetizing field $H_{\mathrm{m}} B(\sigma) H_{\mathrm{m}}$ of $\mathrm{Fe}_{61} \mathrm{Co}_{19} \mathrm{Si}_{5} \mathrm{~B}_{15}$ amorphous alloy cores: (a) in as quenched state, (b) annealed in $410^{\circ} \mathrm{C}$ without magnetic field, (c) annealed in $410{ }^{\circ} \mathrm{C}$ in magnetic flux density of $0.3 \mathrm{~T}$.

\section{Conclusions}

Presented results indicate, that the $\mathrm{Fe}_{61} \mathrm{Co}_{19} \mathrm{Si}_{5} \mathrm{~B}_{15}$ amorphous alloy exhibit significant stress sensitivity, both when subjected to thermo-magnetic treatment as well as subjected to annealing without magnetic field. This significant stress sensitivity is caused by the lack of magnetocrystalline anisotropy in amorphous alloys. As a result, magnetoelastic energy have significant influence on total free energy of amorphous alloys [10, 11]. As it was expected, the thermo-magnetic heat treatment changes magnetic and magnetoelastic characteristics due to changes in the total free energy of the sample.
It was observed that the magnetoelastic sensitivity changes with the thermal annealing of the amorphous alloy sample. The highest value was obtained after annealing in $410^{\circ} \mathrm{C}$ for $1 \mathrm{~h}$. However, for the remaining cores, the magnetoelastic sensitivity was also very high.

Presented results confirm that the amorphous $\mathrm{Fe}_{61} \mathrm{Co}_{19} \mathrm{Si}_{5} \mathrm{~B}_{15}$ alloy can be used in the development of magnetoelastic sensors of the compressive stresses $\sigma$. Due to the high magnetoelastic sensitivity such sensors can be used in industrial applications, mechatronic systems, and civil engineering.

\section{Acknowledgments}

Institute of Physics, Slovak Academy of Sciences was supported by the bilateral project APVV-Sk-PL-0043-12.

Institute of Metrology and Biomedical Engineering, Warsaw University of Technology was supported by the statutory funds within Polish-Slovak bilateral cooperation.

\section{References}

[1] D.C. Jiles, Introduction to Magnetism and Magnetic Materials, Chapman and Hall, London 1998.

[2] A. Bienkowski, J. Kulikowski, J. Magn. Magn. Mater. 19, 120 (1980).

[3] A. Bieńkowski, J. Kulikowski, J. Magn. Magn. Mater. 101, 122 (1991).

[4] T. Kulik, J. Ferenc, A. Kolano-Burian, X. Liang, M. Kowalczyk, J. Alloys Comp. 434, 623 (2007).

[5] A. Pressman, in: Switching Mode Power Supply Design, McGraw-Hill, New York 1998.

[6] J. Salach, L. Hasse, R. Szewczyk, J. Smulko, IEEE Trans. Magn. 48, 1494 (2012).

[7] E. du Trémolet de Lacheisserie, J. Magn. Magn. Mater. 25, 251 (1982).

[8] A. Bienkowski, R. Szewczyk, R. Kolano, Mater. Sci. Eng. A 375-377, 1024 (2004)

[9] I. Škorvánek, J. Marcin, J. Turcanová, M. Wójcik, K. Nesteruk, D. Janickovic, P. Švec, J. Magn. Magn. Mater. 310, 2494 (2007)

[10] M.J. Sablik, D.C. Jiles, IEEE Trans. Magn. 29 2113 (1993).

[11] R. Szewczyk, A. Bienkowski, J. Salach, J. Magn. Magn. Mater. 320, e1049 (2008). 